\title{
AUTONOMÍA DE LA VOLUNTAD Y SELECCIÓN EMBRIONARIA EN EL MARCO DE LAS TÉCNICAS DE REPRODUCCIÓN ASISTIDA*
}

\author{
AUTONOMY OF THE WILL AND EMBRYO SELECTION WITHIN THE \\ ASSISTED REPRODUCTIVE TECHNOLOGY FRAMEWORK
}

\author{
ANDREa MaCía Morillo**
}

\begin{abstract}
Resumen: Los deseos y aspiraciones de los individuos de concebir una descendencia sana o que responda a unas determinadas características se enfrentan y chocan con la protección que los ordenamientos jurídicos ofrecen a la vida en todos los estadios de su desarrollo. En el ámbito de la reproducción humana asistida, esta controversia se manifiesta entre el respeto a la autonomía de la voluntad de los potenciales progenitores en materia de selección embrionaria y su limitación en protección de la vida en estado embrionario. Los distintos ordenamientos jurídicos se han enfrentado de diversos modos a esta controversia, siendo el análisis de las diferentes soluciones a la misma el objeto de este trabajo.
\end{abstract}

Palabras clave: autonomía de la voluntad, selección embrionaria, diagnóstico genético preimplantacional.

Abstract: The desires and aspirations of individuals to conceive healthy offspring or offspring with specific characteristics go against and clash with the protection that the legal systems offer to life at all stages of development. In the field of assisted human reproduction, this controversy manifests itself between the respect for the autonomy of the will of the potential parents in terms of embryo selection and its limitation on the protection of life in an embryonic state. The different legal systems have faced this controversy in different ways; the object of this paper is to analyse the different solutions.

Keywords: autonomy of the will, embryo selection, preimplantation genetic diagnosis.

SUMARIO: I. PLANTEAMIENTO DEL PROBLEMA; II. LIMITACIONES TÉCNICAS Y CIENTÍFICAS A LA AUTONOMÍA DE LA VOLUNTAD EN MATERIA DE SELECCIÓN EMBRIONARIA; III. LIMITACIONES LEGALES A LAAUTONOMÍA DE LA VOLUNTAD EN MATERIA DE SELECCIÓN EMBRIONARIA; 1. Sistemas jurídicos de autorización limitada;

* http://doi.org/10.15366/rjuam2018.38.011

Fecha de recepción: 5 de noviembre de 2018.

Fecha de aceptación: 19 de diciembre de 2018.

** Profesora Contratada Doctora de Derecho civil. Universidad Autónoma de Madrid.

Este trabajo es fruto de la investigación desarrollada en dos proyectos sucesivos: «Retos actuales de la autonomía privada» (DER2014-52503-P), dirigido por M $\mathrm{M}^{\mathrm{a}}$ E. Gómez Calle y J. M M Miquel González y «La libertad de autodeterminación en las relaciones familiares y sus límites como desafío del Derecho de familia del siglo XXI en España y América Latina» (CEAL-AL/2017-20), dirigido por A. Mª Rodríguez Guitián. 


\begin{abstract}
A. Autorización por parte de una entidad u organismo público; B. Limitación autoimpuesta por los propios profesionales intervinientes en el proceso de selección embrionaria; C. Limitación establecida en la regulación sobre diagnóstico genético preimplantacional y selección embrionaria; 2. Sistemas jurídicos que carecen de regulación legal al respecto; IV. CONCLUSIÓN; V. BIBLIOGRAFÍA.
\end{abstract}

\title{
I. PLANTEAMIENTO DEL PROBLEMA
}

Desde el inicio de los tiempos, la principal preocupación de todo futuro progenitor ha estado centrada en la salud y en el perfecto estado de su descendencia: que sus hijos nazcan sanos y que se encuentren bien es una de las primeras aspiraciones que aparecen en la mente de los sujetos que conciben o que se plantean dar este paso. En consonancia con esta preocupación, y en auxilio de los potenciales progenitores, la ciencia médica y el desarrollo científico, técnico y tecnológico han tratado de avanzar progresivamente en la predicción de las enfermedades que pueden afectar a la descendencia futura, así como, en la medida de lo posible, en su terapia; han tratado, pues, en definitiva, de contribuir a poner en manos de los individuos el control sobre su futura descendencia.

Una de las principales herramientas que ha contribuido a proporcionar este control ha venido ofrecida de la mano de las técnicas de reproducción asistida, que comienzan a desarrollarse y a extenderse desde el último cuarto del pasado siglo XX. En concreto, el avance que estas técnicas suponen no solo se manifiesta en materia fertilidad humana, sino, igualmente -y con el auxilio de la técnica complementaria del diagnóstico genético preimplantacional-, en materia de control sobre el posible resultado exitoso de la consiguiente gestación. En un momento histórico en el que la terapia génica todavía se encuentra lejos de las posibilidades reales de la ciencia médica y en el que, consiguientemente, los individuos no cuentan aún con la opción de curar o sanar todos los defectos genéticos que pueden transmitir a su descendencia o que esta puede desarrollar en el proceso de fecundación, el diagnóstico genético preimplantacional ${ }^{1}$ practicado en el contexto de una técnica de fecundación in vitro permite a estos mismos sujetos, al menos, impedir el nacimiento de niños afectados por este tipo de defectos o enfermedades, por medio de la selección embrionaria. Proporciona, por tanto, una valiosa herramienta que otorga a los sujetos un cierto control sobre su descendencia futura y el estado de salud la misma, pero que, al mismo tiempo-y por vía de esa misma selección embrionaria-, conlleva el consiguiente descarte o rechazo de aquellos embriones que no alcanzan las expectativas proyectadas por los individuos sobre su descendencia futura.

\footnotetext{
De acuerdo con ROMEO CASABONA, Los genes y sus leyes. El derecho ante el genoma humano, Bilbao-Granada (Comares), 2002, p. 95, se denomina «diagnóstico genético preimplantacional» todo examen con fines diagnósticos que se produce sobre embriones generados in vitro, de forma previa a la implantación en el seno materno.
} 
Esto pone de relieve una problemática o controversia ética que surge del choque que se produce entre los deseos de los individuos de controlar el proceso de procreación y el resultado del mismo, por un lado, y el posible descarte de embriones y la consiguiente terminación anticipada de potenciales proyectos de vida, por otro ${ }^{2}$. Y se trata de una problemática cuya crudeza o cuyo choque con los valores éticos o morales sociales puede plantearse de manera más o menos aguda según cuál sea el deseo o aspiración que pretenden hacer realidad los individuos respecto de su descendencia futura o, consiguientemente, según cuál sea el motivo o la razón que lleva al subsiguiente descarte de los embriones que no alcanzan ese parámetro que ha quedado fijado por las aspiraciones de los futuros progenitores. En otras palabras, el choque entre la autonomía de la voluntad de los individuos y la protección o valoración del bien vida es de distinto calibre según si lo que se pretende por los sujetos que quieren proceder a una selección embrionaria es excluir el nacimiento de un hijo afectado por una determinada enfermedad o defecto genético, o si lo que pretenden -por el contrario- es el nacimiento de un hijo perfecto o con unas determinadas características raciales. En el primer caso, el riesgo latente tras la opción de dar prevalencia a la autonomía de la voluntad de los individuos es el riesgo de una eugenesia negativa; en el segundo, el riesgo de una eugenesia positiva ${ }^{3}$. Aunque generalmente el primero de estos riesgos suele ser más tolerado socialmente -no en vano el objetivo que persigue en estos casos la selección embrionaria es impedir que la descendencia futura padezca defectos o enfermedades-, ello no significa tampoco que su aceptación sea plena y que, consiguientemente, el objetivo que late tras esas aspiraciones de los futuros progenitores deba legitimar cualquier tipo de selección embrionaria. Por otra parte, el hecho de que el riesgo de una eugenesia positiva asociada a una selección embrionaria no basada en criterios terapéuticos tenga una menor aceptación social no implica tampoco que quede siempre excluido el juego de la autonomía de la voluntad de los futuros progenitores en ese tipo de supuestos.

De hecho, la forma en que los diversos ordenamientos jurídicos han resuelto la controversia puesta de relieve entre el reconocimiento de la autonomía de la voluntad de los sujetos y la protección de la vida en sus primeros estadios de desarrollo está lejos de ser uniforme y, de hecho, pone de manifiesto que no existe una única respuesta. En este sentido, el objeto de este trabajo es tratar de mostrar cuáles han sido estas soluciones y cuáles son -si alguno- los límites que se han impuesto a los individuos en materia de selección embrionaria. En otras palabras: en qué medida se admite y tolera en los ordenamientos jurídicos la aspiración de los sujetos de que sus hijos nazcan sanos y que nazcan bien o, incluso, que

2 Una referencia general a las dudas éticas que suscita el diagnóstico genético preimplantacional en ABELLÁN, F., «Diagnóstico genético embrionario y libertad reproductiva en la procreación asistida», $R D G H$, núm. 25, 2006, pp. 22-26 y LANDEWEERD, L. «Prenatal diagnosis and the trouble with eugenics», RDGH, vol. 30,2009 , pp. 35-39 y 44-45.

3 Se denomina «eugenesia positiva» a la que trata de favorecer la transmisión de caracteres estimados deseables, fomentando la procreación; la «eugenesia negativa», en cambio, trata de evitar la transmisión de caracteres apreciados como no deseables. Sobre ambos conceptos y su valoración jurídica, ver ROMEO CASABONA, C.M., Los genes y sus leyes, cit. pp. 136-139, 143 y 158 y ABELLÁN, F., Selección genética de embriones. Entre la libertad reproductiva y la eugenesia, Granada (Comares), 2007, pp. 14 y 152-163. 
puedan concebir y traer a la vida el hijo más perfecto posible, y en qué medida se imponen límites a esta selección embrionaria.

Antes de pasar a ello, no obstante, conviene realizar dos matizaciones previas que contribuyen a aclarar y perfilar mejor el objeto de estas páginas.

Por un lado, al centrar el tema en el juego de la autonomía de la voluntad de los futuros progenitores en la selección embrionaria, somos conscientes de que dejamos sin valorar otro campo de potencial ejercicio de la autonomía de la voluntad con incidencia directa sobre la futura descendencia: el ámbito de la manipulación genética. Ciertamente, desde el punto de vista teórico, las aspiraciones de los sujetos de concebir al niño sano o al niño perfecto pueden tratar de concretarse también mediante la modificación genética de los embriones concebidos a partir de su propio material reproductor; en otras palabras, pueden pretender hacer sus deseos realidad por medio de la creación de un embrión que responda a los mismos. Sin embargo, no vamos a entrar aquí en esta materia por dos razones: la primera es que en este contexto sí suele haber una respuesta uniforme de los diversos ordenamientos, que rechazan este tipo de manipulaciones genéticas cuando no persiguen un fin terapéutico ${ }^{4}$; la segunda, que ya se ha apuntado anteriormente, es que, en el presente estado de la ciencia y de la técnica y de las posibilidades reales de manipulación genética, este supuesto pertenece casi más a la ciencia ficción que a la realidad, y, consiguientemente, plantear que se pueda hacer realidad el deseo de los sujetos de crear el embrión perfecto carece actualmente de respaldo científico. Por estos motivos, aquí vamos a centrarnos en la reproducción asistida y en la posible realización de las aspiraciones de los futuros progenitores mediante la selección embrionaria.

Por otro lado, hemos de aclarar que, hoy por hoy, la controversia ética que se plantea entre el ejercicio de la autonomía de la voluntad en materia de selección embrionaria y la protección de la vida en sus primeros estadios de desarrollo no puede evitarse adelantando esta selección a un momento anterior al de la concepción y menos controvertido. En concreto, aunque se pretendiera tratar de adelantar temporalmente esta selección y realizarla sobre los gametos masculino o femenino -antes, pues, de la fecundación-, ello no es técnicamente posible en todos los casos ni ofrece las mismas garantías de éxito de la selección de la futura descendencia. Téngase en cuenta, en primer lugar, que un análisis genético que permita la supervivencia del gameto analizado solo parece posible de momento respecto al gameto femenino, pero difícilmente para el masculino. Ahora bien, aun siendo teóricamente posible un diagnóstico sobre el óvulo no fecundado, el problema que plantearía realizar la selección en este estadio, en segundo lugar, es que esta se realizaría únicamente con la información

4 Sirva de ejemplo lo previsto en el artículo $159.1 \mathrm{CP}$, que tipifica el delito de manipulación genética y que es interpretado en sentido estricto, equiparando la manipulación con la alteración del genotipo. Véase al respecto nuestro anterior estudio en MACÍA MORILLO, A., «Límites penales a la autonomía de la voluntad en la selección embrionaria mediante diagnóstico genético preimplantacional», en CANCIO MELIÁ, M. et al. (coords.), Homenaje al Profesor Agustín Jorge Barreiro, Madrid (UAM Ediciones), 2018, apartado II.1.a (pendiente de publicación), así como la doctrina allí citada. 
de la potencial herencia genética que pueda aportar la madre, pero no proporcionaría en cambio ninguna información sobre la otra mitad de la herencia genética del futuro ser -la aportada por el padre- ni permitiría descartar otro tipo de defectos genéticos que se pueden producir con ocasión de la fecundación y el proceso de meiosis celular (las anomalías cromosómicas numéricas o estructurales) ${ }^{5}$. Consiguientemente, en el estado actual de desarrollo de la ciencia médica, la única selección que ofrece posibilidades reales de proporcionar a los individuos los resultados que pretenden con la misma es la que se desarrolla sobre el embrión tras la práctica de un diagnóstico genético preimplantacional en el contexto de las técnicas de reproducción humana asistida.

\section{LIMITACIONES TÉCNICAS Y CIENTÍFICAS A LA AUTONOMÍA DE LA VOLUNTAD EN MATERIA DE SELECCIÓN EMBRIONARIA}

Siendo el diagnóstico genético preimplantacional la principal herramienta con que los individuos pueden contar para hacer realidad sus aspiraciones de concebir una descendencia sana o, incluso, una descendencia perfecta, hemos de poner de relieve desde un principio, no obstante, que esta misma herramienta impone una serie de límites a estos deseos de los potenciales progenitores, que derivan del estado actual del desarrollo científico y de la información que puede ofrecer hoy esta técnica de diagnóstico.

En concreto, lo primero que debe tenerse en cuenta a este respecto es que se trata de una técnica de diagnóstico genético y que, por tanto, por medio de la misma solo se pueden identificar enfermedades o características ligadas a los genes del embrión. En cambio, el desarrollo embrionario posterior a la implantación en el seno materno puede dar lugar a otras enfermedades que no tienen un origen genético, sino patológico o derivado de traumatismos producidos durante el embarazo. Por tanto, el diagnóstico genético preimplantacional no es una garantía de nacimiento de un niño sano, sino de que el embrión implantado es el que reúne las características genéticas buscadas por los usuarios de las técnicas de reproducción asistida.

Por otra parte, en segundo lugar, debe partirse de la idea de que el diagnóstico genético preimplantacional es una técnica que proporciona información sobre los 23 pares de cromosomas de cada embrión fecundado y que permite determinar si se encuentran presentes en el embrión (o si, por el contrario, existe una anomalía cromosómica numérica) y cómo están (si existe o no, por tanto, una anomalía cromosómica estructural o una enfermedad monogénica). Ahora bien, actualmente esta información no es ni puede ser completa y excluyente de cualquier tipo de defecto o afección de tipo genético. En concreto, hay que tener en cuenta que el estado actual del desarrollo científico no permite diagnosticar más

\footnotetext{
5 Tal es, de hecho, la objeción que suele oponerse a la técnica de diagnóstico genético preimplantacional basada en la biopsia de los corpúsculos polares. Por todos, SANZ, E.; ARREO, V.; DÍAZ, M.V.; MOZO, Y. y ALCOBENDAS, R., «Diagnóstico preimplantacional. Características e indicaciones», Toko-ginecología práctica, vol. 69-3, 2010, p. 56.
} 
que un pequeño porcentaje de las enfermedades genéticas conocidas asociadas a un gen determinado (enfermedades monogénicas) ${ }^{6}$ y que, consiguientemente, el examen de un embrión concreto no garantiza la ausencia de enfermedades genéticas distintas de las que se están tratando de identificar concretamente en él. Aunque cada vez más se avanza en esta línea, aún hoy el diagnóstico genético preimplantacional se plantea como una técnica de descarte de alguna determinada afección genética o de un número concreto de estas, pero no como una herramienta que puede ofrecer información sobre el catálogo completo de enfermedades genéticas conocidas ${ }^{7}$.

A ello debe añadirse que las limitaciones técnicas que aún hoy afectan a este tipo de diagnóstico - por la tecnología empleada, el tamaño de las muestras y las limitaciones temporales a que se ve sometido-influyen en gran medida en lo que realmente puede identificarse por medio del diagnóstico genético preimplantacional ${ }^{8}$. En otras palabras, por mucho que los individuos pretendan por medio de esta vía seleccionar un embrión que no se vaya a ver afectado por afecciones de tipo genético, esta pretensión se enfrenta a las propias limitaciones de lo que realmente puede conocerse del estado del embrión en esa fase previa a la implantación en el útero materno. Consiguientemente, y más allá de cualquier consideración ética, la autonomía de la voluntad de los sujetos se enfrenta aquí a un límite fáctico insuperable: el límite de los propios conocimientos científicos y de lo que la medicina y la técnica les permite conocer, a fin de, en su caso, poder escoger.

Con todo, y con las limitaciones puestas de relieve, lo cierto es que el estado actual de la ciencia médica -a través del diagnóstico genético preimplantacional- sí permite identificar no todas, pero sí una serie de afecciones de tipo genético ${ }^{9}$, sean asociadas a un determinado gen (enfermedades monogénicas), sean producidas por una anomalía cromosómica (estructural o numérica) heredada de los progenitores o generada durante la fecundación y la meiosis celular. En ese sentido, ofrece potencialmente a los individuos una valiosa herramienta ya mencionada que les permite seleccionar entre los embriones generados, a fin de -al menos- excluir los afectados por esas enfermedades de tipo genético que el estado actual de la ciencia sí permite identificar. Afirmado esto, no obstante, la cuestión es si estas técnicas permiten algo más y si realmente pueden proporcionar a los potenciales progeni-

6 La cifra se encuentra en torno a las 200 (RAMOS FUENTES, F.J. y RIBAS MOLINA, M.P., «Diagnóstico genético preimplantacional», Revista española de pediatría, vol. 63-6, 2007, p. 446), lo que no alcanza el 10\% de las aproximadamente 3.000 enfermedades genéticas conocidas: ALKORTA IDIAKEZ, I., Regulación jurídica de la medicina reproductiva, Cizur Menor (Thomson-Aranzadi), 2003, pp. 45 a 46.

7 Sobre estas limitaciones, véase RAMOS FUENTES, F.J. y RIBAS MOLINA, M.P., «Diagnóstico genético preimplantacional», cit., p. 447; KRAMP, A., Arzthaftung bei fehlerhafter Präimplantationsdiagnostik, BadenBaden (Nomos), 2015, pp. 43-44 y HARPER, J.C., «Preimplantation genetic screening», J. Med. Screening, 2017, p. 1.

8 Un extenso estudio al respecto en MACÍA MORILLO, A., Diagnóstico genético preimplantacional y responsabilidad médica por falsos negativos, Madrid (Reus), 2018, pp. 181 a 188.

9 Un resumen de los diversos tipos de afecciones genéticas, su probabilidad y sus características puede encontrarse en MACÍA MORILLO, A., Diagnóstico genético preimplantacional y responsabilidad médica por falsos negativos, cit., pp. 67 a 72, con referencia a la doctrina especializada. 
tores un instrumento a través del cual pretendan hacer valer sus deseos de concebir no ya al hijo sano, sino al que reúna las características que ellos pretenden encontrar presentes en su descendencia y que no van asociadas a un concepto terapéutico o de salud del embrión.

La respuesta a esta pregunta es afirmativa, siempre y cuando tales características buscadas se asocien a rasgos genéticos y siempre y cuando exista previamente el conocimiento científico sobre el gen o genes en los que dichos rasgos se expresan. Así, por ejemplo, a través del llamado diagnóstico genético preimplantacional extensivo ${ }^{10}$, el estado de la ciencia actualmente permitiría identificar indudablemente a los embriones de un determinado sexo, así como a los que reúnan unas ciertas características de HLA-compatibilidad o histocompatibilidad con respecto a otros individuos ya nacidos ${ }^{11}$. Del mismo modo, hay que pensar que puede y podrá identificar ahora y en un futuro más o menos próximo otros rasgos físicos, raciales o de capacidades de los individuos (fuerza, velocidad, inteligencia), que puedan ser deseadas por los potenciales progenitores y que vayan ligadas a un determinado gen.

Eso sí, hay que puntualizar que ello será posible siempre y cuando dicho gen sea potencialmente transmisible por sus progenitores; no olvidemos que la técnica de diagnóstico preimplantacional solo permite obtener una información de lo que está presente o no en los embriones, pero no modifica éstos. Por tanto, por medio de la aplicación de esta técnica será posible, en su caso, escoger al embrión que reúna estas características buscadas, pero solo si tales características se encuentran en alguno de los embriones de la muestra obtenida ${ }^{12}$, ya que si ninguno de ellos presenta dichas características, tal selección será obviamente imposible y solo cabrá o bien el descarte de todos los embriones o bien la renuncia por parte de los individuos a sus deseos y la implantación de un embrión que no reúne los rasgos buscados.

\section{LIMITACIONES LEGALES A LAAUTONOMÍA DE LA VOLUNTAD EN MATERIA DE SELECCIÓN EMBRIONARIA}

Habiendo sentado en el apartado anterior el marco fáctico en el que realmente es posible en la actualidad la selección embrionaria, llega el momento de examinar cuáles son las limitaciones que los diversos ordenamientos han impuesto -en su caso- al ejercicio de la autonomía de la voluntad en esta materia, en mor de la protección de la vida en sus primeros estadios de desarrollo. Desde el punto de vista teórico, el abordaje legal del

10 Véase esta terminología en ABELLÁN, F., «Diagnóstico genético embrionario y libertad reproductiva en la procreación asistida», cit., p. 38.

${ }_{11}$ El HLA es una proteína determinada por el patrón antigénico de las personas que se encuentra en las células y tejidos y es usada por el sistema inmunológico para distinguir entre células propias o ajenas (ARANGO RESTREPO, P.; SÁNCHEZ ABAD, P.J. y PASTOR, L.M., «Diagnóstico genético preimplantatorio y el bebé medicamento: criterios éticos encontrados en la literatura biomédica y bioética», Cuadernos de Bioética, vol. 23-2, 2012, pp. 303 a 304).

12 Por medio de la estimulación ovárica previa con la que se inicia el procedimiento (SANZ, E., et al., «Diagnóstico preimplantacional», cit., pp. 55 a 56.) se trata de ampliar al máximo posible el tamaño de la muestra sobre la que aplicar la selección, pero, aun así, la selección se limita a esa muestra. 
problema ético que hemos puesto de relieve desde las primeras páginas de este trabajo puede responder a una de estas cuatro opciones: 1. prohibición absoluta de la selección embrionaria y exclusión del juego de la autonomía de la voluntad de los individuos en esta materia; 2. autorización ilimitada de la selección embrionaria y plena libertad de ejercicio de la autonomía de la voluntad en este campo; 3. establecimiento de límites a la selección embrionaria y, consiguientemente, ponderación del conflicto ético entre la autonomía de la voluntad y la protección de la vida en función del motivo en el que se pretende basar la selección embrionaria; y 4. falta de regulación sobre la cuestión.

A la hora de determinar cuál de estas cuatro respuestas es la que se ha adoptado en un determinado ordenamiento jurídico, interesa tener en cuenta que, generalmente, el establecimiento de una regulación sobre esta materia suele concentrarse en torno al diagnóstico genético preimplantacional, siendo la selección embrionaria una consecuencia derivada de la admisión legal de la práctica del mismo. Dicho de otra forma, allí donde se admite este tipo de diagnóstico, se admite la selección embrionaria posterior y, allí donde se prohíbe, correlativamente se impide tal selección. Otra cosa lleva al absurdo de permitir que los individuos conozcan el estado o las características de su potencial descendencia, pero que no tengan reconocida la libertad de hacer algo al respecto. El diagnóstico genético preimplantacional y la selección embrionaria ulterior parecen, por tanto, ser un binomio en la regulación legal de esta cuestión.

Esto, sin embargo, no siempre ha sido así en la práctica, como muestra la situación que se produjo en Italia tras la regulación introducida por la Legge, de 19 de febrero de 2004, n. 40, in materia di procreazione medicalmente assistita (en lo sucesivo, Ley 40/2004). Pese a que el tenor literal del artículo 14.5 de esta norma parece admitir que una pareja solicite información sobre el estado de salud de los embriones (lo que remite indirectamente al diagnóstico genético preimplantacional), tras su promulgación se planteó una clara duda respecto a si, tras la práctica de un hipotético diagnóstico, era en absoluto posible una selección embrionaria, en la medida en que el apartado 1 del mismo precepto excluía la crioconservación o el descarte de los embriones y en que el apartado 2 disponía la implantación única e inmediata de los embriones fecundados. De hecho, una primera interpretación estricta de estas normas llevó a afirmar al Tribunal de Catania (Ordinanza de 3 de mayo de $2004^{13}$ ) que existía un deber de implantar todos los embriones producto de una técnica de reproducción asistida, incluso los enfermos, dejando posteriormente a juicio de la mujer si abortar o no, en caso de que se produjese la implantación y arraigo de estos últimos. Aunque las críticas a este pronunciamiento judicial han sido numerosas ${ }^{14}$, lo cierto es que los preceptos que han dado lugar a la duda siguen parcialmente vigentes ${ }^{15}$. Pese a ello, la jurisprudencia pos-

\footnotetext{
13 Prima Sezione civile; núm. 4612/04 (Giur. It., pp. 2088 y ss.).

14 Por todos, MOROZZO DELlA ROCCA, P., «Tribunale di Catania. Ordinanza 3 maggio 2004. Procreazione medicalmente assistita e beta-talassemia», DFP, vol. 1, 2005, pp. 97 a 104.

15 En 2005 se planteó un referéndum para la derogación de este y otros aspectos de la legislación italiana. No obstante, no se alcanzó el mínimo de participación necesario para que el voto mayoritario a favor de la derogación tuviera efecto. Posteriormente, la Corte Costituzionale ha declarado en 2009 la inconstitucionalidad
} 
terior ha superado esa primera línea estricta de interpretación de la norma y ha admitido en diversas ocasiones la selección embrionaria posterior a la práctica del diagnóstico genético preimplantacional ${ }^{16}$, apoyándose para ello en la idea de que esta implantación ulterior no es coercible $^{17}$. Recientemente, el propio Tribunale Constitucionale italiano ha apoyado también esta misma línea, en su sentencia de 11 de noviembre de $2015^{18}$, que, pronunciándose sobre la inconstitucionalidad de otros preceptos de la Ley 40/2004 (en concreto, los artículos 13.3.b y 13.4), legitima la selección embrionaria cuando su finalidad exclusiva es evitar la implantación de embriones afectos por una enfermedad genética transmisible. Por tanto, hay una tendencia clara en Italia a establecer una coherencia lógica entre la admisión de la práctica del diagnóstico genético preimplantacional y la selección embrionaria posterior, en la línea de lo que aquí hemos afirmado.

Partiendo, pues, de este binomio que se forma entre el diagnóstico genético preimplantacional y la selección embrionaria, puede afirmarse que cada vez son menos los Estados que optan por la solución de la prohibición absoluta. De hecho, en los últimos años hemos asistido a la desaparición de la doble prohibición legal a este tipo de diagnóstico que se podía encontrar en Italia (que únicamente autorizaba su práctica para las parejas infértiles o estériles y solo con fines «observacionales») y en los países de la órbita germana (donde, por la influencia de los eventos históricos, se había consagrado tradicionalmente una exacerbada protección a la dignidad de la persona ${ }^{19}$ ). En el primero de tales Estados, la interpretación judicial de la norma y la intervención de las altas cortes nacionales e internacionales ha ido eliminando, sucesivamente, la prohibición del uso del diagnóstico genético preimplantacional ${ }^{20}$ y la restricción

de los artículos 14.2 y 14.3 de la Ley 40/2004 (Sentencia de 8 de mayo de 2009, n. 151; Giur. Cost., 2009, pp. 1688 y ss.), pero nada ha establecido sobre la posible selección entre los embriones que habría que implantar o el destino de los no implantados.

16 En concreto, Ordinanza del Tribunale di Firenze, de 17 de diciembre de 2007 (F. it., I, 2008, pp. 632 y ss.); Ordinanza del Tribunale di Bologna de 29 de junio de 2009 (Fam. i Dir., 2009, pp. 1854 y ss.); Sentencia del Tribunale di Salerno, de 9 de enero de 2010 (F. it., 2010, I, pp. 1018 y ss.) y Ordinanza del Tribunale di Cagliari, de 9 de noviembre de 2012 (Nuova G. Civ. Comm., 2013, I, pp. 67 y ss.).

17 De hecho, ya el primer desarrollo reglamentario de la Ley 40/2004 (Decreto de 21 de julio de 2004 del Ministerio de la Salud), pese a ser el responsable de su interpretación estricta, admitía expresamente esta incoercibilidad de la implantación de los embriones identificados como afectados. Coincide con ello JORQUI AZOFRA, M., «El Tribunal de Cagliari (Italia) da luz verde al diagnóstico genético preimplantacional», RDGH, vol. 27, 2007, pp. 162 a 166 .

18 Sentencia n. 229 (Corr. giur., 2016, pp. 185 y ss.).

19 BAYEFSKY, M.J., «Comparative preimplantation genetic diagnosis policy in Europe and the USA and its implications for reproductive tourism», Reprod. BioMedicine \& Society Online, vol. 3, 2016, p. 44.

20 En concreto, ya la Sentencia del Tribunale Amministrativo Regionale del Lazio, de 21 de enero de 2008 (Giur. Mer., 2008, pp. 1144 y ss.) declaró la nulidad de la restricción del diagnóstico genético preimplantacional a meros fines de «observación», contenida en el Decreto de 21 de julio de 2004 del Ministerio de la Salud, que se eliminó en las versiones subsiguientes de 2008 y 2015. Este pronunciamiento fue seguido posteriormente por otras sentencias en supuestos análogos; v. gr., Sentencia de 22 de septiembre de 2007 del Tribunale di Cagliari (Nuova G. Civ. Comm., 2008, I, pp. 249 y ss.), Ordinanza del Tribunale di Firenze, de 17 de diciembre de 2007 (F. it., I, 2008, pp. 632 y ss.) y Ordinanza del Tribunale di Bologna, de 29 de junio de 2009 (Fam. $i$ Dir., 2009, pp. 1854 y ss.). 
de su acceso a las parejas fértiles ${ }^{21}$; en los segundos, progresivamente se han producido las respectivas reformas legales que han abierto al campo a la práctica de este diagnóstico, aunque de forma limitada ${ }^{22}$. Más allá de que esta prohibición directa o indirecta pueda subsistir en algunos ordenamientos ${ }^{23}$, lo cierto es que, en un mundo cada vez más globalizado, este tipo de prohibiciones pueden quedar a menudo sin efecto real, en la medida en que los individuos que quieran tener acceso a estas prácticas se desplacen a estos Estados para su ejecución. El «turismo reproductivo» también se manifiesta, por tanto, en este ámbito ${ }^{24}$, poniendo en jaque la eficacia de las prohibiciones absolutas y forzando a los ciudadanos de estos Estados a viajar al extranjero para hacer valer sus deseos y aspiraciones.

Del mismo modo, tampoco es frecuente adoptar la solución contraria: esto es, que un determinado ordenamiento opte por admitir de forma absoluta la selección embrionaria y reconocer plenamente la libertad de los individuos en el ejercicio de su autonomía reproductiva. De hecho, hasta donde llega nuestro conocimiento, es una opción meramente teórica. El patente choque ético y moral ya puesto de relieve entre tal ejercicio y la protección de la vida en sus primeros estadios de desarrollo suele aparecer como un obstáculo general al reconocimiento expreso de una facultad de selección embrionaria ilimitada, al servicio de la voluntad y de los caprichos de los individuos.

Las opciones más frecuentes, por tanto, y en las que nos vamos a detener en las siguientes páginas, se centran, por un lado, en la admisión limitada de la facultad de selección embrionaria y, por otro, en la falta de regulación sobre la materia. En esa tesitura, hemos de llamar la atención, no obstante, respecto de que, como vamos a ver, esta última solución produce o puede producir de facto el mismo efecto de libertad absoluta, que, como acabamos de decir, se suele evitar de iure.

${ }^{21}$ De hecho, tal restricción ha sido eliminada definitivamente por la Sentencia de la Corte Costituzionale de 5 de junio de 2015, n. 96 (F. it., 2015, I, pp. 2250 y ss.), pronunciada pocos años después del famoso caso Costa y Pavan v. Italia, resuelto por el Tribunal Europeo de Derechos Humanos en el año 2012 (STEDH, Sección $2^{\mathrm{a}}$, de 28 de agosto de 2012, núm. 54270/10, §§ 56-57. Versión definitiva ante la Grande Chambre de 11 de febrero de 2013), donde se consideró contraria al artículo 8 del Convenio Europeo de Derechos Humanos la incoherencia de tal limitación en un Estado que admitía para esas mismas parejas el recurso a la interrupción voluntaria del embarazo.

22 Alemania es el primer país germano que admite este tipo de diagnóstico, frente a la prohibición tradicional, al reformar en el año 2011 su regulación que databa de 1990. Recientemente, le han seguido Austria (en 2015) y Suiza (en 2017).

23 La prohibición es indirecta en aquellos Estados en los que se afirma, por ejemplo, el reconocimiento de la personalidad jurídica desde la concepción, como ocurría con Argentina anteriormente a la reforma del Código civil y comercial de la Nación producida en el año 2015.

24 Para una visión general de este fenómeno del «turismo reproductivo», sus costes y consecuencias para las parejas afectadas, véase BAYEFSKY, M.J., «Comparative preimplantation genetic diagnosis policy in Europe and the USA and its implications for reproductive tourism», cit., pp. 42 y 45 a 46. 


\section{Sistemas jurídicos de autorización limitada}

La mayor parte de los ordenamientos que desarrollan una normativa sobre diagnóstico genético preimplantacional lo regulan de forma limitada, de manera que el acceso al mismo por parte de los usuarios de las técnicas de reproducción asistida no es libre ni queda a su plena voluntad. La forma de establecer esta limitación, no obstante, varía, pudiendo identificarse tres sistemas distintos para el establecimiento o reconocimiento de los límites.

\section{A. Autorización por parte de una entidad u organismo público}

El primer sistema es aquel en el que la práctica del diagnóstico genético preimplantacional y la subsiguiente selección embrionaria quedan condicionadas a la autorización del procedimiento por parte de una determinada entidad o instancia. Ejemplo de ello parece ser el caso del Reino Unido, en el que la Human Fertilisation and Embriology Authority (en lo sucesivo, «HFEA») tiene atribuida la competencia para autorizar a los centros encargados de la ejecución de estas técnicas (Section 11 de la Human Fertilisation and Embryology Act 1990; en lo sucesivo, «Act 1990») y, consiguientemente, indirectamente interviene y limita la práctica de las mismas.

De forma más directa incluso, en el caso de la regulación alemana, el § 3a (3) 2 Embryonenschutzgesetz (en lo sucesivo, ESchG) condiciona la práctica de este diagnóstico a la valoración positiva previa de la concurrencia del supuesto habilitante, por parte de una comisión ética ${ }^{25}$. Y en nuestro ordenamiento, el artículo 12.2 de la Ley 14/2006, de 26 de mayo, sobre Técnicas de Reproducción Humana Asistida (en lo sucesivo, «LTRHA») contempla un proceso de legitimación indirecta para la práctica de este diagnóstico, que queda condicionado a la autorización de la autoridad sanitaria competente, previo informe favorable de la Comisión Nacional de Reproducción Humana Asistida, «que deberá evaluar las características clínicas, terapéuticas y sociales de cada caso $»^{26}$. En concreto, dentro del amplio contexto de licitud de la práctica del diagnóstico genético preimplantacional y la selección embrionaria que contiene nuestra regulación, este segundo apartado del artículo 12 LTRHA incluye los casos en los que no puede realizarse de manera general o automática la ponderación de intereses de los usuarios de estas técnicas frente a la protección de la vida en sus primeros estadios de desarrollo, por existir un mayor disenso social respecto de cuál de los intereses en juego ha de pesar más en esos casos en los que se incrementa el riesgo de una eugenesia positiva. Ello desaconseja una legitimación apriorística del diagnóstico genético preimplantacional y aconseja, por el contrario, el examen y ponderación de todos

\footnotetext{
25 El desarrollo reglamentario de la norma en 2013 dispone que, para la concesión de la autorización para la práctica del diagnóstico preimplantacional, se tendrán en cuenta no solo aspectos médicos (que son el presupuesto), sino también psíquicos, sociales y éticos (§ 6 (4) Präimplantationsdiagnostikverordnung).

26 En igual sentido, ABELLÁN, F., «Diagnóstico genético embrionario y libertad reproductiva en la procreación asistida», cit., pp. 26 a 27, se refiere a la autorización directa e indirecta.
} 
los factores e intereses que interactúan en el caso concreto ${ }^{27}$. El resultado de estas mayores cautelas es que esta intervención preceptiva y autorización previa limita o puede limitar la realización de los deseos y aspiraciones de los individuos en relación a su descendencia futura, por medio de la selección embrionaria.

\section{B. Limitación autoimpuesta por los propios profesionales intervinientes en el proceso de selección embrionaria}

Como segunda vía de limitación o, más bien, de reconocimiento de la existencia de límites, nos encontramos con las restricciones que los propios actores e intervinientes en el proceso de reproducción asistida, diagnóstico genético preimplantacional y selección embrionaria se imponen a sí mismos, bien por desconocimiento de la extensión exacta de la regulación legal en su concreto ordenamiento jurídico, o bien por miedo a las consecuencias de la transgresión de los límites impuestos por dicha regulación. Dos ejemplos son ilustrativos de estos casos.

Así, por un lado, en nuestro ordenamiento, como acabamos de mencionar, el artículo 12.2 LTRHA impone la previa obtención de una autorización para la práctica del diagnóstico genético preimplantacional en dos supuestos: «para cualquiera otra finalidad no comprendida en el apartado anterior» $\mathrm{y}$ «cuando se pretendan practicar en combinación con la determinación de los antígenos de histocompatibilidad de los preembriones in vitro con fines terapéuticos para terceros». Frente a ello, sin embargo, en los supuestos contemplados en el apartado anterior (artículo 12.1), la legitimación para proceder a la práctica de este diagnóstico es directa y no dependiente de autorización alguna; únicamente se impone un deber de «comunicar» la aplicación de estas técnicas a la autoridad sanitaria competente. Pese a ello, por desconocimiento de esta regulación o por excesiva cautela o prudencia, no es infrecuente que se solicite por parte de los profesionales médicos la autorización y el dictamen de la Comisión Nacional de Reproducción Humana Asistida en todo procedimiento de diagnóstico genético preimplantacional, incluso aunque el caso concreto se enmarque sin duda alguna en el supuesto de hecho contemplado por el artículo 12.1 LTRHA.

Por otro lado, en segundo lugar, la situación que se vivió en Alemania con anterioridad a la reforma de la Embryonenschutzgesetz en 2011 es una clara muestra de cómo el miedo a las consecuencias de la transgresión de la norma inspira en ocasiones también una cautela excesiva a los profesionales médicos involucrados en estas técnicas, que redunda

27 En este sentido, la doctrina española valora positivamente la autorización preceptiva, como opción «prudente» del legislador (LACADENA, J. R., «La Ley 14/2006 sobre Técnicas de Reproducción Humana Asistida, consideraciones científicas y éticas», RDGH, vol. 24, 2006, p. 173) o como incremento de las garantías de un uso racional de este diagnóstico (OSUNA CARRILLO DE ALBORNOZ, E. y ANDREU MARTÍNEZ, M. B., «Artículo 12. Diagnóstico preimplantacional», en COBACHO GÓMEZ, J. A. (dir.), Comentarios a la Ley 14/2006, de 26 de mayo, sobre Técnicas de reproducción asistida, Cizur Menor (Thomson-Aranzadi), 2007, p. 450). 
en la limitación de su práctica y, consiguientemente, de la atención de los deseos de los potenciales progenitores. En concreto, la regulación originaria alemana del año 1990 parecía excluir casi completamente la práctica del diagnóstico genético preimplantacional y la consiguiente selección embrionaria. La base para ello se encontraba fundamentalmente en la combinación de una serie de preceptos de la norma germana, entre ellos el § 2 (1), que establece la prohibición del uso de embriones humanos para un fin que no conlleve su preservación y que se ponía en relación con el $\S 8$ (1), que realiza una interpretación amplia del concepto de «embrión» que incluye cualquier célula con la capacidad de desarrollar por sí misma un organismo humano ${ }^{28}$. Sobre una interpretación estricta de la norma, se entendía excluida cualquier forma de diagnóstico genético preimplantacional que se produjera sobre el embrión in vitro en alguna fase en la que las células del mismo tuvieran todavía la característica de ser totipotentes (es decir, con capacidad para desarrollarse como un organismo humano pleno) $)^{29}$.

Tal regulación, no obstante, dejaba con todo un resquicio a la licitud de la práctica de dicho diagnóstico, en la medida en que no se practicara sobre células del embrión o en la medida en que el estadio de desarrollo embrionario hubiera llegado ya a la fase en el que las células son simplemente pluripotentes (con capacidad para desarrollarse como cualquier órgano o tejido) $)^{30}$; en concreto, dejaba un resquicio a la práctica de este diagnóstico a través del análisis de células del trofoectodermo ${ }^{31}$. Con todo, los profesionales médicos alemanes, conscientes de que la norma limitadora de este tipo de prácticas tenía un carácter penal, no se arriesgaban a ensayar comportamientos que pudieran forzar la interpretación de la regulación, por miedo a resultar castigados ${ }^{32}$.

La prueba, sin embargo, de que tales resquicios existían y de que, en efecto, podía admitirse la práctica de un diagnóstico genético preimplantacional vino de la mano del Tribunal Supremo alemán, que -resolviendo precisamente un caso en el que un médico había tentado esos supuestos límites-afirmó la licitud de la práctica del diagnóstico genético preimplantacional sobre células del trofoectodermo, haciendo un llamamiento al legislador

28 TAUPITZ, J., «§ 3a Präimplantationsdiagnostik. Verordnungsermächtigung», en Embryonenschutzgesetz. Juristischer Kommentar mit medizinisch-naturwissenschaftlichen Grundlagen, $2^{\mathrm{a}}$ ed., Stuttgart (W. Kohlhammer), 2014, p. 279.

29 Esta afirmación es indiscutida en Alemania, según TAUPITZ, J., «§ 3a Präimplantationsdiagnostik», cit., pp. 281 y 294; o KRAMP, A., Arzthaftung bei fehlerhafter Präimplantationsdiagnostik, cit., p. 57.

${ }_{30}$ Sobre las características de las células como totipotentes o pluripotentes, ver KRAMP, A., Arzthaftung bei fehlerhafter Präimplantationsdiagnostik, cit., p. 37.

31 El trofoectodermo o trofoblasto es una masa celular desarrollada en la fase de blastocisto, de la que posteriormente se genera la placenta. No afecta, por tanto, a la masa del embrioblasto, de la que se generará posteriormente el embrión. Ver al respecto KRAMP, A., Arzthaftung bei fehlerhafter Präimplantationsdiagnostik, cit., p. 39.

32 Los autores alemanes se refieren en este punto a una «prohibición fáctica». Así, TAUPITZ, J., «§ 3a Präimplantationsdiagnostik», cit., p. 279 y KRAMP, A., Arzthaftung bei fehlerhafter Präimplantationsdiagnostik, cit., pp. 59 y 62. 
alemán para que regulara y aclarara la cuestión ${ }^{33}$. Tal llamamiento, de hecho, encontró rápida respuesta con la reforma que se promulgó en el año 2011, que definitivamente incorporó los supuestos de licitud de este tipo de práctica ${ }^{34}$.

\section{Limitación establecida en la regulación sobre diagnóstico genético preimplantacional y selección embrionaria}

En tercer lugar -y, de hecho, como vía más frecuente de limitación de la autonomía de la voluntad de los sujetos-, se encuentran los ordenamientos en los que se condiciona expresamente la práctica del diagnóstico genético preimplantacional y la selección embrionaria a la presencia en el caso concreto de una serie de presupuestos, que actúan así como indicaciones habilitantes para el mismo. De hecho, cuando se piensa en un sistema de autorización limitada de la práctica de la selección embrionaria, se está tomando generalmente este tipo de supuestos como modelo o parámetro.

Tal limitación, no obstante, puede ser mayor o menor, en función de los criterios que se utilicen para ello, por lo que, consiguientemente, la correlativa libertad y el posible ejercicio de la autonomía de la voluntad en esta materia puede ser más amplio o más restringido. Examinando la panorámica de los diversos ordenamientos, los criterios que se toman en cuenta para establecer estos límites o indicaciones que permiten el diagnóstico genético preimplantacional y la subsiguiente selección embrionaria son los siguientes.

\section{i. Afecciones genéticas hereditarias o anomalías genéticas espontaneas:}

Diversos ordenamientos condicionan y limitan la práctica de este tipo de diagnóstico y selección embrionaria posterior a los supuestos en los que se ha constatado en uno o ambos progenitores la presencia de una determinada enfermedad o afección genética. Uno de los mejores ejemplos de ello es el caso de Francia, cuyo artículo L. 2131-4 (4) Code de la Santé limita la práctica del diagnóstico genético preimplantacional a la identificación de una anomalía presente en uno de los progenitores o, en casos especiales, de sus ascendientes directos. Con ello, consciente o inconscientemente se rechaza la potencial selección de otras afecciones de tipo genético pero de aparición espontánea durante la fecundación, como son las anomalías cromosómicas numéricas ${ }^{35}$.

El motivo que late tras esta limitación se centra en el hecho de que, allí donde no existe una previa afección genética constatada, la posible anormalidad genética de los embriones

\footnotetext{
33 Se trata de la Sentencia del Bundesgerichtshof, de 6 de julio de 2010 (5. StR 386/09; BGHSt 55, 206).

34 Véase el iter legislativo de la norma, en KRAMP,A.,Arzthaftung bei fehlerhafter Präimplantationsdiagnostik, cit., pp. 64 a 67.

${ }_{35}$ El texto, procedente de 2004, no fue revisado en ese sentido en la reforma realizada por la Ley n. 2011814, de 7 de julio, relative à la bioéthique, ya que la cuestión estaba asentada (y, como señala VIGNEAU, D., «Les dispositions de la loi "bioéthique" du 7 juillet 2011 relatives à l'embryon et au foetus humain», $R D$, vol. 32, 2011, p. 2228, preocupaba más la regulación del diagnóstico prenatal).
} 
es una cuestión de probabilidad, aunque ciertamente incrementada en presencia de determinados indicios (ej.: edad avanzada de la gestante, abortos previos de repetición) ${ }^{36}$. Por esta razón, incluso en estos casos se habla en consonancia de un «cribado genético» más que de un «diagnóstico genético» ${ }^{37}$.

Con todo, este criterio de limitación no está generalizado, y también encontramos ordenamientos en los que se admite el diagnóstico genético preimplantacional y subsiguiente selección embrionaria sobre afecciones genéticas que se generan espontáneamente en el proceso de fusión de los gametos masculino y femenino. Tal es, de hecho, el supuesto contemplado en nuestro artículo 12.1.b LTRHA. El límite aquí, no obstante, queda establecido por la exigencia de que la afección genética incida sobre la «viabilidad» del embrión, lo que reserva la selección embrionaria para los supuestos en los que los embriones afectados ven gravemente comprometidas sus expectativas de vida por razón de la anomalía genética. Para el resto de las anomalías cromosómicas estructurales o numéricas de aparición espontánea, en la medida en que no impliquen un riesgo potencial a la viabilidad del embrión (v.gr., la trisomía del cromosoma 21 o síndrome de Down), la práctica del diagnóstico genético preimplantacional queda condicionada a la autorización previa ya mencionada anteriormente. En otras palabras, la libertad de los sujetos para seleccionar y excluir la implantación de los embriones afectados por anomalías genéticas de aparición espontánea que no afecten a la viabilidad de los propios embriones queda limitada y sometida al procedimiento de autorización de la práctica del diagnóstico genético preimplantacional previo, ex art. 12.2 LTRHA $^{38}$.

\section{ii. Gravedad de la afección genética:}

A diferencia del anterior, este segundo criterio es un límite común en la mayoría de sistemas de autorización limitada ${ }^{39}$, a menudo reforzado por la exigencia de que no exista un tratamiento curativo conocido ${ }^{40}$. De hecho, en el contexto de las enfermedades hereditarias asociadas al sexo, la exigencia de gravedad aparece también en textos internacionales, como el artículo 14 del Convenio para la protección de los Derechos humanos y la dignidad del ser humano con respecto a las aplicaciones de la biología y la medicina (Convenio relativo a los derechos humanos y a la biomedicina), hecho en Oviedo el 4 de abril de 1997 y ratificado

\footnotetext{
36 Sobre estos indicios, ver, por todos, SANZ, E., et al., «Diagnóstico preimplantacional», cit., p. 58.

37 Ver la diferencia entre ambos en HARPER, J. C., «Preimplantation genetic screening», cit., p. 1.

38 Como ya apuntamos en otro sitio (MACÍA MORILLO, A., Diagnóstico genético preimplantacional y responsabilidad médica por falsos negativos, cit., pp. 105-106), otra cosa es que los profesionales médicos puedan pretender interpretar aquí ampliamente el concepto de afectación a la viabilidad de los embriones.

39 Según SOINI, S., «Preimplantation genetic diagnosis (PGD) in Europe: diversity of legislation, a challenge to the community and its citizens», Med. \& Law, vol. 26, 2007, pp. 317 a 318, es compartido por todas las legislaciones.

40 Ver en este sentido nuestro artículo 12.1.a LTRHA, así como los artículos L. 2131-4 (3) Code de la Santé de Francia, 5a.2.c FMedG de Suiza o el § 2a (2) FMedG de Austria.
} 
por España y en vigor desde 1 de enero de 2000 (en lo sucesivo, Convenio de Oviedo), que rige en 29 países del territorio europeo ${ }^{41}$.

Siendo un límite generalizado, no siempre es sencillo determinar exactamente su extensión, pues ni su determinación ni su forma de delimitarlo es coincidente en todos los Estados. Así, por ejemplo, existen ordenamientos en los que se recurre a un sistema de listas o ejemplificaciones de las enfermedades que se consideran graves y que, consiguientemente, pueden permitir la selección embrionaria. Muestras de ello, paradigmáticamente, son el Reino Unido, donde la HFEA elabora y mantiene actualizada una lista con las situaciones en las que se puede acudir a un diagnóstico genético preimplantacional, que contiene más de 60 enfermedades ${ }^{42}$; así como, en menor medida, el caso de Andalucía, donde el Anexo II del Decreto 156/2005, de 28 de junio, de la Comunidad Autónoma de Andalucía, incluye una lista de 8 enfermedades genéticas «graves» a las que les es aplicable el diagnóstico genético preimplantacional.

Frente a ello, sin embargo, países como Francia o Alemania rechazan expresamente este sistema de listas, en atención o como prevención al potencial riesgo de estigmatización de los afectados por estas dolencias ${ }^{43}$. De hecho, son más los Estados que, por el motivo indicado o por otro no expresado -como ocurre en España ${ }^{44}-$, no disponen de una lista de enfermedades graves, lo que traslada entonces el problema a determinar qué afecciones entran en este concepto y cuáles no.

Ante este panorama, hay quien ha sugerido trasladar a este ámbito la interpretación de ese mismo adjetivo que se ha ido elaborado por la jurisprudencia en materia de interrupción voluntaria del embarazo ${ }^{45}$. Sin embargo, esta analogía entre el aborto y la selección embrionaria no es adecuada, y hay autores que la rechazan ${ }^{46}$. A partir de aquí, la definición

${ }^{41}$ Véase la lista actualizada en $<$ https://rm.coe.int/inf-2017-7-rev-etat-sign-ratif-reserves/168077dd22>. [Consultado el 04/11/2018].

42 Puede consultarse esta lista en $<$ https://www.hfea.gov.uk/pgd-conditions/>. [Consultado el 02/11/2018].

43 En el caso de Francia, el Comité Consultatif National d'Éthique pour les Sciences de la Vie et de la Santé se pronunció en ese sentido en 2009 («Avis sur les problèmes éthiques liés aux diagnostics anténatals: le diagnostic prénatal (DPN) et le diagnostic préimplantatoire (DPI)», núm. 107, p. 26). En Alemania, esta idea se encuentra en autores como TAUPITZ, J., «§ 3a Präimplantationsdiagnostik», cit., p. 290.

44 Pese a las oportunidades que han existido y existen de disponer de tal lista en nuestro ordenamiento, esta no se ha elaborado todavía. De hecho, el Gobierno nunca cumplió la obligación que le imponía al respecto la Disposición final d) de la Ley 35/1988, de 22 de noviembre, sobre Técnicas de Reproducción Asistida, y dicha obligación no fue reiterada en la actual Ley 14/2006. Por otra parte, si bien el artículo 3.4 del Real Decreto 42/2010, de 15 de enero, por el que se regula la Comisión Nacional de Reproducción Humana Asistida, atribuye a este órgano la función de proponer listas de enfermedades genéticas y hereditarias que reúnan dudas acerca de su inclusión en los supuestos recogidos en el artículo 12.1 LTRHA, de momento tales listas no parecen haberse elaborado o, al menos, publicado.

45 Así, en España lo sugieren OSUNA CARRILLO DE ALBORNOZ, E. y ANDREU MARTÍNEZ, M. B., «Artículo 12», cit., p. 448 nota 38; y en el ordenamiento alemán, FROMMEL, M., «Die Neuregelung der Präimplantationsdiagnostik durch $\S 3^{\text {a }}$ Embryonenschutzgesetz», JZ, vol. 68-10, 2013, p. 491.

46 Contundentemente, por ejemplo, TAUPITZ, J., «§ 3a Präimplantationsdiagnostik», cit., pp. 289 a 290. 
o concreción del límite a la autonomía de la voluntad y a la selección embrionaria puede venir por dos vías más o menos complementarias: la vía de identificar las características que deben tenerse en cuenta para calificar una enfermedad genética de «grave» (vía que parece haberse adoptado en Alemania ${ }^{47}$, uustria $^{48} \mathrm{y}$, en cierta medida, en España ${ }^{49}$ ), o la vía de dejar la definición al caso concreto y al juicio de los profesionales médicos. Esta última, de hecho, es la que en la práctica acaba siendo la más frecuente.

De hecho, aunque no existe tampoco un consenso pleno en el ámbito médico sobre lo que deba considerarse «grave» en relación a las afecciones genéticas ${ }^{50}$, pues es muy extenso el número de los casos dudosos, los profesionales médicos están acostumbrados a realizar este tipo de valoraciones ${ }^{51} \mathrm{y}$ debemos aceptar que son los que tienen una mayor y más consciente visión de las enfermedades, su incidencia en el cuerpo humano y sus consecuencias. Por ello, en última instancia, la determinación de este límite suele quedar en todos los ordenamientos en manos de los profesionales médicos, en atención a las circunstancias de cada caso concreto.

\section{iii. Edad de manifestación de la afección o anomalía genética}

Algunos ordenamientos incluyen como límite a la práctica del diagnóstico genético preimplantacional y posterior selección embrionaria el requisito de que la enfermedad que vaya a afectar a la descendencia sea de aparición temprana. El razonamiento que late tras la imposición de este límite a la autonomía de la voluntad de los futuros progenitores reside en que el sujeto afectado por una enfermedad de manifestación tardía ha tenido la oportunidad

47 Según TAUPITZ, J., «§ 3a Präimplantationsdiagnostik», cit., p. 290 y KRAMP, A., Arzthaftung bei fehlerhafter Präimplantationsdiagnostik, cit., p. 97, en los trabajos preparatorios de la reforma de 2011, el legislador alemán aludía en este punto a la esperanza de vida, los síntomas de la enfermedad y su tratamiento en comparación con otras enfermedades, como criterios no cumulativos que debe tener en cuenta la comisión ética que autoriza el diagnóstico.

48 El $\S 2$ a (2) FMedG enumera tres circunstancias en las que se aprecia la gravedad de la enfermedad hereditaria: 1. Cuando supone que el mantenimiento de la vida del sujeto precisa de cuidados o de medios de auxilio médico o técnico; 2. Cuando se manifiesta en una lesión cerebral grave; 3. Cuando causa dolores permanentes que no se pueden tratar de una forma eficaz.

49 El artículo 5.3.8.3.f.ii del Anexo III RD 1030/2006, al definir el diagnóstico genético preimplantacional cuya práctica queda incluida en la cartera de servicios de la Seguridad Social, remite a que la enfermedad de base genética: «comprometa la esperanza y/o calidad de vida por producir anomalías congénitas, discapacidad intelectual, sensorial o motora, no susceptibles de un tratamiento curativo con arreglo a los conocimientos científicos actuales».

50 Así lo afirman KNOPPERS, M. M.; BORDET, S. e ISASI, R. M., «Preimplantation genetic diagnosis: an overview of socio-ethical and legal considerations», Annu. Rev. Genom. Hum. Genet., vol. 7-1, 2006, pp. 207 a 208. Según LANDEWEERD, L. «Prenatal diagnosis and the trouble with eugenics», cit., pp. 42 o 50, el problema radica en que, en última instancia, la gravedad de una enfermedad es un concepto subjetivo.

51 Así lo ponen de relieve ALKORTA IDIAKEZ, I., Regulación jurídica de la medicina reproductiva, cit., p. 323; ABELLÁN, F., Selección genética de embriones, cit., p. 11 y OSUNA CARRILLO DE ALBORNOZ, E. y ANDREU MARTÍNEZ, M. B., «Artículo 12», cit., p. 448. 
de disfrutar de muchos años en perfectas condiciones de salud ${ }^{52}$ y que es posible que, de hecho, no llegue a alcanzar la edad en la que se manifiesta la anomalía genética o que, para ese momento, se haya descubierto una terapia curativa ${ }^{53}$. En ese contexto, por tanto, se puede considerar que no es aceptable el rechazo o descarte de los embriones afectados por dichas dolencias futuras. Tal es, de hecho, el criterio de nuestro artículo 12.1.a LTRHA (que exige que la enfermedad genética sea de aparición «precoz») o del artículo 5a.2.b FMedG de Suiza (con un límite retrasado a 50 años).

Lo cierto, sin embargo, es que se trata de un límite controvertido en sí, tanto desde el punto de vista jurídico ${ }^{54}$, como desde el punto de vista médico ${ }^{55}$. Téngase en cuenta, por ejemplo, que la práctica muestra que la edad en que se manifiestan las enfermedades puede variar en los distintos individuos, llegando a diferenciarse, incluso, en décadas ${ }^{56}$. Consiguientemente, puede ser arbitrario identificar una determinada cifra de edad que distinga entre las enfermedades de aparición precoz y las tardías ${ }^{57}$.

Por este motivo, una limitación basada en la edad de manifestación de las enfermedades genéticas que permiten acudir a la selección embrionaria no se encuentra en todos los ordenamientos que regulan esta técnica. Es más, podemos encontrar ejemplos de autorización de tal selección para enfermedades de aparición tardía ${ }^{58}$ y silencios legales que equivalen a una autorización tácita de este tipo de diagnósticos ${ }^{59}$.

52 Esta problemática se refleja en las dudas que apunta LACADENA, J. R., «La Ley 14/2006 sobre Técnicas de Reproducción Humana Asistida, consideraciones científicas y éticas», cit., p. 171.

53 ABELLÁN, F., «Diagnóstico genético embrionario y libertad reproductiva en la procreación asistida», cit., p. 42.

54 Véanse las observaciones de ABELLÁN, F., Selección genética de embriones, cit., pp. 114 a 125.

55 Como muestra de este debate, ver, entre otros, FLORENSA, M., «Diagnóstico genético preimplantacional para enfermedades de aparición tardía», Rev. Asoc. Est. Biol. Rep., vol. 16-1, 2011, pp. 45 a 46 y CUADROS, J., «Diagnóstico preimplantacional para evitar la aparición tardía de enfermedades», Rev. Asoc. Est. Biol. Rep., vol. 16-1, 2011, p. 46.

56 MANCINI, F.; BOADA, M. y BARRI, P. N., «Considerazioni etiche sulla procreazione medicalmente assistita», Revista de Bioética y Derecho, n. ${ }^{\circ}$ 23, 2011, p. 41.

57 Ver estas críticas en TAUPITZ, J., «§ 3a Präimplantationsdiagnostik», cit., p. 291, respecto del límite fijado en el ordenamiento alemán al diagnóstico prenatal.

58 Así, por ejemplo, la HFEA ha autorizado el diagnóstico genético preimplantacional para diversas enfermedades de aparición tardía (ABELLÁN, F., «Diagnóstico genético embrionario y libertad reproductiva en la procreación asistida», cit., pp. 28 y 42). Igualmente, esta autorización ha sido concedida por nuestra Comisión Nacional de Reproducción Humana Asistida, por ejemplo, para la detección del gen BRCA1, responsable del cáncer hereditario de mama y ovario.

59 En concreto, en Alemania la falta de mención expresa de este límite en el diagnóstico genético preimplantacional lleva a afirmar la ausencia del mismo, ya que sí está impuesto expresamente para excluir y limitar el diagnóstico prenatal, para enfermedades que se manifiestan pasados los 18 años. Ver al respecto, TAUPITZ, J., «§ 3a Präimplantationsdiagnostik», cit., p. 290. 


\section{iv. Selección limitada a los embriones afectados o extendida a los portadores}

Otra cuestión controvertida y no resuelta de igual forma (o no resuelta en general) en los diversos ordenamientos jurídicos es si la facultad de selección embrionaria se debe limitar a los embriones que han sido reconocidos como afectados por la enfermedad o defecto que se trata de identificar por medio del diagnóstico genético preimplantacional o si se puede extender y permitir también la selección y el descarte de los meros portadores de estas afecciones; es decir, embriones que, de desarrollarse como individuos, no van a verse afectados en sí mismos por dicha enfermedad o defecto, pero que pueden transmitir esta a su descendencia. La misma indefinición, por ejemplo, se muestra en los textos internacionales, como el Convenio de Oviedo, cuyo artículo 12 remite la licitud de las pruebas genéticas predictivas a las que permiten identificar a un individuo como «portador» de una enfermedad genética o con predisposición a la misma, redacción esta que, aunque parece inclinarse por el criterio más amplio ${ }^{60}$, siembra la duda de si lo hace en un sentido técnico.

En el caso español, por ejemplo, la Ley 14/2006 no aborda expresamente la cuestión, como habría sido deseable, y suscita la duda de si la práctica de estos diagnósticos sigue la vía de la legitimación directa o si deben someterse a autorización previa ${ }^{61}$. El artículo 9.3 de la Ley 14/2007, de 3 de julio, de Investigación Biomédica (en lo sucesivo, LIB) tampoco es claro a este respecto, puesto que, aunque afirma la licitud de la práctica de pruebas predictivas (genéticas) «que permitan identificar al sujeto como portador de un gen responsable de una enfermedad», puede dudarse con ello no se está refiriendo solo a los individuos ya nacidos (y no a los embriones) ${ }^{62}$.

En Alemania o en el Reino Unido la cuestión tampoco se aborda directamente, pero parece admitirse implícitamente ${ }^{63}$. De hecho, esta selección de los embriones portadores de afecciones genéticas es tratada, curiosamente, no desde la perspectiva de su descarte, sino precisamente desde la perspectiva contraria; esto es, la perspectiva de la posible implantación de tales embriones. En ambos países, se afirma, pues, la posible selección positiva y consiguiente implantación de los mismos (condicionada a que no haya otros embriones sanos, conforme a la Section 13 (9) y (10) Act 1990 del Reino Unido; o sometida a la libre

60 De hecho, ABELLÁN, F., «Diagnóstico genético embrionario y libertad reproductiva en la procreación asistida», cit., pp. 32 y 33, interpreta justamente lo contrario, sobre la redacción del artículo 14 del mismo texto legal.

${ }_{61}$ Ver al respecto MACÍA MORILLO, A., Diagnóstico genético preimplantacional y responsabilidad médica por falsos negativos, cit., pp. 103 a 104.

62 Nuestra doctrina parece inclinarse por la respuesta afirmativa y la admisión de la selección embrionaria sobre meros portadores. A ello parece apuntar, por ejemplo, EMALDI CIRIÓN, A., «Voz: Diagnóstico preimplantatorio», en ROMEO CASABONA, C. M. (dir.), Enciclopedia de Bioderecho y Bioética, Granada (Comares), 2011, pp. 638 a 639 o SOUTULLO, D., «Selección de embriones y principios de la bioética», RDGH, vol. 21, 2004, p. 191.

63 Así, por ejemplo, para Alemania, KRAMP, A., Arzthaftung bei fehlerhafter Präimplantationsdiagnostik, cit., pp. 193 y 309 . 
voluntad de la usuaria de las técnicas de reproducción asistida, en el caso de Alemania ${ }^{64}$ ), solución esta que parece chocar con la adoptada por el legislador español, al disponer en el artículo 12.1.a LTRHA únicamente la posible transferencia de los embriones «no afectos» ${ }^{65}$.

\section{v. Rasgos de histocompatibilidad del embrión con respecto de otro sujeto}

Entrando en el ámbito del respeto o reconocimiento del ejercicio de la autonomía de la voluntad no basado en un criterio terapéutico o de salud del embrión seleccionado, sino en otros rasgos del mismo, hay que mencionar de forma destacada la posible selección basada en la HLA-compatibilidad de los embriones con respecto de un sujeto ya concebido y nacido. Se trata, por tanto, de los supuestos del denominado «bebé salvador»o «bebé medicamento», contemplados dentro del llamado diagnóstico genético preimplantacional extensivo.

En estos casos, al conflicto ético ya planteado anteriormente entre el respeto a la autonomía de la voluntad de los individuos y la protección de la vida en los estadios iniciales de su desarrollo, se añade un segundo y no descartable conflicto ético o moral que reside en la supuesta cosificación o instrumentalización del embrión así seleccionado, que se concibe como un medio para lograr un fin que le es ajeno y respecto del que no puede manifestar una voluntad positiva: la curación de un tercero ${ }^{66}$. Tales conflictos se muestran de forma especialmente cruda si se tiene en cuenta que, en el contexto de este tipo de diagnósticos, la probabilidad de identificar un embrión histocompatible con el tercero es relativamente baja (3/16) y que, para aumentar tal posibilidad, se suele incrementar el número de embriones generados ${ }^{67}$, lo que suele conllevar correspondientemente, por criterios probabilísticos, el descarte de un número de embriones mayor del normal en cualquier otro procedimiento de diagnóstico genético preimplantacional y selección embrionaria. El hecho de que en este

64 Tal y como pone de relieve FROMMEL, M., «Die Neuregelung der Präimplantationsdiagnostik durch §

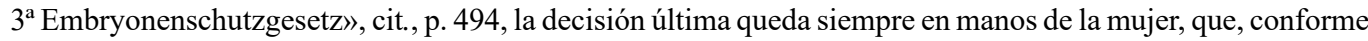
al $§ 4 E S c h G$, puede negarse siempre a la trasferencia de los embriones.

65 A diferencia de la regulación originaria contenida en la Ley 35/1988, que únicamente «desaconsejaba» esta transferencia, la actual Ley 14/2006 parece excluirla de manera absoluta. Más allá de las dudas que esta reforma pueda plantear en relación a su propia constitucionalidad (en atención a la doctrina del Tribunal Constitucional contenida en el FJ 12 STC 116/1999, de 17 de junio), lo cierto es que la norma puede resultar excesiva si se entienden incluidos en esta prohibición de implantación los embriones meramente portadores de enfermedades genéticas. Quizá, por ello, parece preferible entender que sí cabe para éstos la práctica del diagnóstico genético preimplantacional, pero no por la vía directa del artículo 12.1.a LTRHA-que parece conducir inevitablemente a su descarte-, sino por la del artículo 12.2, en la que la autorización de la autoridad sanitaria competente ya tomará en cuenta el posible destino de estos embriones portadores para fines reproductivos de los usuarios de estas técnicas.

66 Un resumen de los argumentos a favor y en contra de este tipo de diagnósticos desde el punto de vista de la ética en ARANGO RESTREPO, P. et al., «Diagnóstico genético preimplantatorio y el bebé medicamento», cit., pp. 307 a 314.

${ }_{67}$ ARANGO RESTREPO, P. et al., «Diagnóstico genético preimplantatorio y el bebé medicamento», cit., pp. 304 a 305 . 
caso se trate de embriones generalmente sanos puede determinar que el destino de los que resulten no ser HLA-compatibles sea la crioconservación (para la implantación posterior en la pareja de la que proceden), o la donación a otra pareja, pero ello no tiene por qué ser así, y -según lo que contemplen los diversos ordenamientos- pueden igualmente acabar descartados o inutilizados para los fines de la concepción (véase, en nuestro caso, la regulación del artículo 11.4 LTRHA y, en Francia, el artículo 2131-4 (7) Code de la Santé).

Con todo, este grave conflicto ético se ha resuelto en positivo en parte de los ordenamientos jurídicos, y existen diversos Estados que admiten aquí la selección embrionaria y el juego de la autonomía de la voluntad de los individuos. De hecho, tal es el caso, por ejemplo, de España (art. 12.2 LTRHA), Francia (art. 2131-4-1 Code de la Santé) o Reino Unido (Schedule 2 1ZA.1.d Act 1990). Ahora bien, las diferencias entre los diversos ordenamientos, no obstante, no solo se manifiestan en si se admite o no este tipo de selección embrionaria, sino, igualmente -allí donde se admite-, en cuál es el presupuesto para su admisión.

En concreto, debe destacarse que algunos países admiten tal diagnóstico extensivo y la subsiguiente selección embrionaria únicamente si por medio del mismo también se puede beneficiar al embrión seleccionado mismo; es decir, únicamente cuando la selección tiene el doble objetivo de identificar y escoger al embrión histocompatible con un tercero que, además, no se ve afectado él mismo por la afección genética que padece dicho sujeto ya nacido ${ }^{68}$. En otros ordenamientos, por el contrario, no siendo este beneficio del embrión objeto de diagnóstico preimplantacional un requisito para llevar a cabo el mismo, sí que se condiciona la práctica de este tipo de diagnóstico a una autorización previa, por parte de la autoridad competente, que examine las circunstancias del caso (por ejemplo, a fin de comprobar que existe una verdadera voluntad procreativa en los potenciales progenitores y no una mera instrumentalización del futuro ser al servicio del ya nacido) ${ }^{69}$.

Por otra parte, las diferencias también se manifiestan en la limitación o extensión del sujeto -beneficiario y beneficiado por el nacimiento del nuevo ser así seleccionado y posteriormente concebido- que puede tenerse en cuenta para llevar a cabo este tipo de selección embrionaria. Así, ordenamientos como Francia o Reino unido, lo restringen a los «hermanos»y otros, como España, hablan, genéricamente, de «terceros» ${ }^{70}$.

68 Tal restricción parece encontrarse en Reino Unido, donde la autorización del diagnóstico extensivo por parte de la HFEA se ha limitado al contexto de enfermedades hereditarias (transmisibles y potencialmente presentes en todos los descendientes de unos mismos progenitores), pero no para el de enfermedades espontáneas. Ver DE LORA DELTORO, P., «¿Es permisible tener un hijo para curar a otro?», BMJ, vol. 2179, 2015, pp. 43 a 44.

69 Tal es el caso de España, conforme al artículo 12.2 LTRHA, así como de Francia, según el artículo L. 2131-4-1 Code de la Santé Publique (introducido por la reforma del mismo del año 2011).

70 Como señala GONZÁLEZ MORÁN, L., De la bioética al bioderecho: libertad, vida y muerte, Madrid (Dykinson), 2006, p. 707, es notable que la Exposición de Motivos de la Ley 14/2006 únicamente se refiera a que la selección embrionaria pueda servir de ayuda «para salvar la vida del familiar enfermo». 


\section{vi. Selección del sexo del embrión}

La atención que se presta a los deseos de los futuros progenitores en relación con el sexo de su futura descendencia es diferente según cuál sea la causa que motive esta preferencia por uno u otro sexo. Así, esta voluntad es generalmente atendida y respetada cuando el motivo que fundamenta la pretendida selección va asociado al intento de evitar una enfermedad genética asociada al cromosoma sexual; prueba patente de ello es la regulación del Reino Unido (Schedule 2 1ZA.1.c Act 1990). Es más, tal aspiración resulta también amparada en textos internacionales como el Convenio de Oviedo, cuyo artículo 14 contempla precisamente la utilización de las técnicas de reproducción asistida para la selección de sexo en caso de enfermedades graves hereditarias asociadas al cromosoma sexual.

Su admisión para finalidades distintas y no asociadas a la salud de la futura descendencia-la selección de sexo, por tanto, con fines sociales- es, por el contrario, aceptada en muy menor medida y, de hecho, suele ser rechazada de forma categórica, por sus posibles consecuencias $^{71}$. Muestra de ello es el caso español, que, pese a la amplitud con la que contempla la posible práctica del diagnóstico genético preimplantacional, parece excluir completamente la selección basada en el sexo del embrión, al tipificar como sanción muy grave en el artículo 26.2.c.10a LTRHA (con multa por tanto desde 10.001 a un millón de euros, ex art. 27.1), «la selección de sexo (...) con fines no terapéuticos o terapéuticos no autorizados». Así lo apreció, de hecho, la STAP-Barcelona de 12 de noviembre de 1990, cuando revocó la autorización a la práctica de la selección de un embrión de sexo femenino, concedida en primera instancia a una mujer, madre de cinco hijos varones ${ }^{72}$. La selección del sexo con fines sociales queda, pues, excluida incluso del sistema de autorización contemplado en el artículo 12.2 LTRHA $^{73}$.

Con todo, es de destacar en este punto la aparente paradoja que supone la limitación absoluta de la autonomía de la voluntad de los individuos en relación a estas características sexuales de los embriones, frente a la previsión legal en nuestro mismo ordenamiento de un sistema de interrupción voluntaria del embarazo plenamente libre en las primeras 14 semanas, conforme a lo dispuesto en el artículo 14 de la Ley Orgánica 2/2010, de 3 de marzo, de Salud Sexual y Reproductiva y de la Interrupción Voluntaria del Embarazo. En otras palabras, la autonomía de la voluntad que se limita en el estadio inicial de la vida humana se puede ejercitar libremente poco después, tras la implantación del embrión en el seno materno. Aunque con esto no pretendemos afirmar que la decisión de selección embrionaria sea igual o tenga la misma trascendencia que la decisión de interrumpir voluntariamente

71 En este sentido, FOX, D., «Reproductive negligence», Colum. L. Rev., vol. 117, 2017, p. 237, que incide en las desigualdades que estas prácticas consolidan.

72 Ver la referencia completa del caso en PÉREZ ALONSO, E. J., «Consideraciones críticas sobre la regulación legal de la selección de sexo (Parte I)», RDGH, vol. 16, 2002, pp. 66 a 69.

73 En contra de la selección de sexo por motivos no terapéuticos, ABELLÁN, F., Selección genética de embriones, cit., p. 107; OSUNA CARRILLO DE ALBORNOZ, E. y ANDREU MARTÍNEZ, M. B., «Artículo 12», cit., pp. 454 a 460 y EMALDI CIRIÓN, A., «Voz: Diagnóstico preimplantatorio», cit., p. 639. 
la gestación ya comenzada, lo cierto es que llama la atención la aparente contradicción del legislador en su voluntad de limitación de las opciones de los potenciales progenitores ${ }^{74}$; quizá por este motivo, países como Noruega o la India prohíben legalmente la averiguación del sexo en fase prenatal.

Esta paradoja es, de hecho, especialmente digna de ser puesta de relieve, si se tiene en cuenta la decisión del Tribunal Europeo de Derechos Humanos manifestada en el caso Costa y Pavan v. Italia. En concreto, el fundamento de la alta corte para afirmar la lesión del artículo 8 del Convenio Europeo de Derechos Humanos se basó fundamentalmente en el argumento de la incoherencia presente en el ordenamiento italiano, que prohibía el diagnóstico genético preimplantacional para las parejas fértiles, al tiempo que les permitía el recurso al aborto, posterior a la implantación ${ }^{75}$. Pues bien, la situación de nuestro ordenamiento parece en este punto análoga a la italiana, puesto que obliga a las parejas que desean concebir únicamente descendencia de un sexo determinado a interrumpir voluntariamente dentro de las primeras 14 semanas el embarazo ya iniciado, si quieren hacer valer sus deseos. Por tanto, salvo que se establezca en nuestro ordenamiento la prohibición de revelación del sexo del embrión durante esas primeras 14 semanas, al estilo de lo establecido en el $\S$ 15 Gendiagnostikgesetz alemán, habría que ver si, planteada ante el Tribunal Europeo de Derechos Humanos un caso como en ya referido de Barcelona, el alto tribunal reiteraría su jurisprudencia, habida cuenta que la selección embrionaria que se pretende en este caso se fundamenta en una cuestión no terapéutica (el sexo) y no en una afección genética.

vii. Limitaciones a la selección de otras características del embrión no relacionadas con fines terapéuticos

En general, los ordenamientos que contienen limitaciones a la autonomía de la voluntad de los individuos en materia de selección embrionaria no suelen contemplar la licitud de la práctica del diagnóstico genético preimplantacional y la consiguiente selección para fines no terapéuticos. Al estar concebida generalmente la autorización para dicho diagnóstico en términos de excepción -como ocurre en la regulación francesa- $\mathrm{o}$, incluso, de despenalización de una conducta punible - como ocurre en la alemana-, ese silencio u omisión respecto de este tipo de características del embrión equivale a una negativa de la práctica de este tipo de técnicas en tales supuestos y, consiguientemente, una limitación de la autonomía de la voluntad de los sujetos en relación a estas pretensiones de selección embrionaria. Excepción a ello podría plantear el caso español, donde la cláusula general del artículo 12.2 LTRHA

\footnotetext{
74 En este sentido, como señalan PUIGPELAT MARTÍ, F., «La selección de sexo: aspectos jurídicos y valoración crítica», RDGH, vol. 6, 1997, p. 104 y PÉREZ ALONSO, E. J., «Consideraciones críticas sobre la regulación legal de la selección de sexo (Parte II)», $R D G H$, vol. 17, 2002, pp. 116, 119 y 123, la admisión de un sistema de aborto de plazos puede dejar en nada esta prohibición, razón por la que estos autores aconsejan eliminarla.

75 Ver especialmente los puntos 58 a 66 de la Sentencia STEDH, Sección 2a , de 28 de agosto de 2012, n. 54270/10, §§ 56-57. Versión definitiva ante la Grande Chambre de 11 de febrero de 2013.
} 
no cierra a priori la puerta a estos supuestos, aunque resulta más que dudoso -al menos en la actualidad-que la autoridad sanitaria competente vaya a autorizar la práctica de un diagnóstico genético preimplantacional en este contexto, contando con un previo informe favorable de la Comisión Nacional de Reproducción Humana Asistida ${ }^{76}$.

Más dudoso todavía resulta -tanto en el ordenamiento español, como en el resto de ordenamientos que regulan el acceso a las técnicas de selección embrionaria de forma limitada-que se admita en general o en concreto la práctica de la selección embrionaria en el contexto del llamado «empeoramiento genético», donde la finalidad de selección perseguida por los potenciales progenitores no ya solo no es que no tenga fines terapéuticos, sino que, incluso, puede considerarse lesiva para los intereses de los embriones ${ }^{77}$. En concreto, en la medida en que los deseos de los individuos en relación a su descendencia futura se manifiesten en la aspiración de que esta se vea afectada por una determinada enfermedad o defecto genético, es sumamente difícil que tal juego de la autonomía de la voluntad sea admitido en el contexto de un sistema de limitación del acceso a la selección embrionaria, no ya tanto en esta ocasión por el choque con la protección de la vida, como por una cierta protección al futuro ser fruto de estas opciones de sus progenitores ${ }^{78}$. Por seguir con el ejemplo del caso español y de su amplia admisión del diagnóstico genético preimplantacional, las pretensiones de los sujetos de empeoramiento genético de su descendencia se verían claramente excluidas, si no por el tipo penal contemplado en el artículo $160.3 \mathrm{CP}$, sí al menos por lo dispuesto en los artículos 3.1 y 12.1.a LTRHA, así como en el artículo 9.3 LIB ${ }^{79}$.

\section{Sistemas jurídicos que carecen de regulación legal al respecto}

Si anteriormente hemos afirmado que, dentro de los ordenamientos que regulan el diagnóstico genético preimplantacional y la selección embrionaria, la mayor parte ha optado por una admisión limitada de estas técnicas, ahora tenemos que afirmar que, en el conjunto de los ordenamientos - esto es, desde una perspectiva global-, la mayor parte guarda silencio sobre esta materia y no la regula expresa ni implícitamente. De hecho, el

76 Téngase en cuenta, por ejemplo, la Recomendación 1100/1989 de la Asamblea Parlamentaria del Consejo de Europa sobre «Investigación científica relativa a los embriones y fetos humanos», de 2 de febrero, que aconseja en el número 4 de su Apéndice no autorizar intervenciones en los embriones que no sean de carácter diagnóstico o con fines de prevención o de terapia en interés del feto.

77 Un estudio sobre los mismos, desde el punto de vista de la responsabilidad de los padres, en SMOLENSKY, K. R., «Creating children with disabilities: parental tort liability for preimplantation genetic interventions», Hastings L.J., vol. 60, 2008, pp. 299 a 346.

78 En este sentido, ABELLÁN, F., «Diagnóstico genético embrionario y libertad reproductiva en la procreación asistida», cit., pp. 26 y 37 y 47 a 48; y JORQUI AZOFRA, M., «El Tribunal de Cagliari (Italia) da luz verde al diagnóstico genético preimplantacional», cit., p. 168, apuntan a una clara limitación del libre albedrío de los potenciales progenitores en el sentido indicado.

79 Véase al respecto nuestro estudio en MACÍA MORILLO, A., «Límites penales a la autonomía de la voluntad en la selección embrionaria mediante diagnóstico genético preimplantacional», cit., apartado II.3, así como la doctrina allí citada. 
número de países que aborda la regulación de estas materias es francamente minoritario, si se compara con el número total de Estados que existen en el mundo ${ }^{80}$. Y es que la mayor parte de los ordenamientos jurídicos parece preferir guardar silencio sobre estas cuestiones, lo que consideramos que se explica por una de las siguientes cuatro razones:

- Ausencia de desarrollo tecnológico en el Estado en cuestión que le permita la práctica y el desarrollo de este tipo de técnicas -altamente complicadas y punteras-, o falta de nivel económico de la población suficiente como para poder permitírselas. En otras palabras, hoy por hoy podemos afirmar que la problemática que aparece reflejada en estas páginas parece más bien propia de países desarrollados del primer mundo, y muy alejada de los problemas que suelen atraer la atención de los legisladores de los países subdesarrollados del tercer mundo.

- Motivos religiosos. Como muestra el caso de Italia hasta la Ley 40/2004, así como de muchos países de Sudamérica, la problemática que late tras el diagnóstico genético preimplantacional y la subsiguiente selección embrionaria tiene un importante sustrato religioso o moral; no olvidemos, de hecho, que la otra cara de la selección embrionaria es o puede ser el descarte de los embriones y la consiguiente terminación anticipada de esos proyectos de vida humana. Esa fuerte oposición religiosa aconseja mantener el silencio legal sobre la materia en países confesionales o con fuerte tradición religiosa y no abrir un debate que puede llevar a regulaciones sumamente restrictivas o a un cisma social.

- Presiones de la profesión médica. En ausencia de regulación y de límites impuestos por el poder público, el mercado de la práctica del diagnóstico genético preimplantacional se desarrolla libremente. Siendo esa la situación, los profesionales médicos, acostumbrados a tal ausencia de límites huyen de la intervención del Estado en la materia - generalmente limitadora- y presionan para mantener la situación de autorregulación ${ }^{81}$.

- Protección de derechos de los individuos frente a la injerencia del Estado. En la medida en que la regulación del Estado en esta materia introduce límites al ámbito de la autonomía de la voluntad de los sujetos en relación a sus aspiraciones y deseos en materia reproductiva y de selección embrionaria, los Estados que mayor valor otorgan a esta libertad del sujeto frente a las injerencias del poder público eluden la imposición de una regulación sobre la materia ${ }^{82}$.

\footnotetext{
80 Véanse referencias concretas normativas en ABELLÁN, F., «Diagnóstico genético embrionario y libertad reproductiva en la procreación asistida», cit., p. 30.

81 Así lo ponen de relieve para el caso de Estados Unidos, por ejemplo, BAYEFSKY, M. J., «Comparative preimplantation genetic diagnosis policy in Europe and the USA and its implications for reproductive tourism», cit., p. 44 y FOX, D., «Reproductive negligence», cit., p. 164.

82 Por todos, KNOPPERS, M. M., et al., «Preimplantation genetic diagnosis: an overview of socio-ethical and legal considerations», cit., p. 216.
} 
Sea por uno u otro motivo, lo cierto es que en estos ordenamientos en los que no existe una regulación sobre la práctica del diagnóstico genético preimplantacional y la consiguiente selección embrionaria la situación es que esta se puede desarrollar sin límite alguno. Sobre el principio de que lo que no está prohibido está permitido ${ }^{83}$, lo cierto es que la situación en tales Estados es equiparable, como ya apuntamos, a la de aquellos otros -hipotéticos a nuestro saber- en los que exista una autorización expresa ilimitada. Así pues, potencialmente, en estos países se puede llevar a cabo el diagnóstico genético preimplantacional para la identificación de cualquiera de las características genéticas del embrión que permita el estado actual de la ciencia médica, procediéndose posteriormente a una selección embrionaria acorde a los deseos y aspiraciones de los potenciales progenitores. Esto incluye, por supuesto, la selección embrionaria basada en criterios terapéuticos, pero igualmente $-\mathrm{y}$ sin límite- la selección embrionaria de otras características del embrión ajenas a un criterio de salud del mismo; esto es, el niño perfecto y también, por qué no, los supuestos de empeoramiento genético.

Ahora bien, que se pueda llegar a estos extremos no significa, sin embargo, que se llegue necesariamente a ellos en todos los Estados en los que no existe regulación legal sobre estas cuestiones. No es de despreciar en este sentido la propia autolimitación que se imponen los profesionales médicos implicados en este tipo de procedimiento, sea por desconocimiento o miedo - como ya destacamos anteriormente-, o sea también por sus propias convicciones morales o éticas ${ }^{84}$. Igualmente, tampoco debe olvidarse en este contexto la labor que desarrollan los comités éticos o las sociedades profesionales, que intervienen elaborando protocolos, directrices o documentos que tratan de establecer límites a la práctica indiscriminada e ilimitada de estas técnicas ${ }^{85}$.

Con todo, y aunque la incidencia de las dos vías de limitación mencionadas es grande, no puede pretenderse, sin embargo, que tengan los mismos efectos o la misma fuerza limitadora que la impuesta por una regulación legal a nivel estatal. De hecho, el valor de los protocolos y códigos éticos es relativo, si se tiene en cuenta que no siempre se pretende con ellos la imposición de límites ${ }^{86}$ y que su posible imposición a los profesionales médicos suele quedar limitada a los miembros de las propias organizaciones o asociaciones en las que éstos

\footnotetext{
83 Véase un desarrollo más extenso en nuestro anterior trabajo MACÍA MORILLO, A., Diagnóstico genético preimplantacional y responsabilidad médica por falsos negativos, cit., pp. 384 a 386.

${ }_{84}$ Una referencia a este límite en SMOLENSKY, K. R., «Creating children with disabilities: parental tort liability for preimplantation genetic interventions», cit., p. 304.

85 Destaca en este sentido el papel de las diversas asociaciones de profesionales médicos del ramo, KNOPPERS, M. M. et al., «Preimplantation genetic diagnosis: an overview of socio-ethical and legal considerations», cit., p. 216.

86 De hecho, a modo de ejemplo, BAYEFSKY, M. J., «Comparative preimplantation genetic diagnosis policy in Europe and the USA and its implications for reproductive tourism», cit., p. 43, se refiere a que algunas de estas directrices solo tienen una pretensión de ser «educacionales».
} 
se elaboran ${ }^{87}$, cuya potestad sancionadora, por otra parte, no siempre se reconoce ${ }^{88}$. A esto debe sumarse que la autolimitación del profesional sanitario se encuentra en franco riesgo, especialmente allí donde existe una mayor competencia y donde las actividades relacionadas con las técnicas de reproducción asistida forman parte de un lucrativo mercado cuya demanda es cada vez más creciente ${ }^{89}$. Frente a sus reparos morales o éticos, el profesional se enfrenta a un doble dilema que puede erosionar su voluntad autolimitadora: la certeza, por un lado, de que el procedimiento que él se niega a realizar será realizado probablemente por otro profesional con menos escrúpulos y la conciencia, por otro, de que la selección embrionaria puede ser, en ocasiones, un mal menor, frente a la alternativa que supone llevar a cabo esta selección con posterioridad a la concepción de un embrión no seleccionado; esto es: realizar esta selección negativa acudiendo a una interrupción voluntaria del embarazo, hasta lograr el resultado perseguido por los potenciales progenitores ${ }^{90}$.

Por ello, en estos ordenamientos en los que no existe una limitación legal al ejercicio de la autonomía de la voluntad de los individuos en materia de selección embrionaria, hemos de llamar la atención respecto a la amplitud del riesgo de una total ausencia de límites y de un consiguiente desequilibrio en la protección de la vida en los estadios iniciales de su desarrollo.

\section{CONCLUSIÓN}

Las páginas precedentes han mostrado las diversas soluciones adoptadas por los distintos ordenamientos jurídicos en la búsqueda de una salida a la controversia ética que se plantea entre el reconocimiento de la autonomía de la voluntad de los sujetos en materia de selección embrionaria y la protección de la vida en los estadios iniciales de su desarrollo. Pero, más allá de una falta de uniformidad, el estudio desarrollado pone de relieve los diversos problemas y la intrínseca insatisfacción que late realmente detrás de cualquiera de estas soluciones. Insatisfacción en el caso de los posicionamientos absolutos, puesto que la

87 Apunta este problema, entre otros, KNOPPERS, M. M. et al., «Preimplantation genetic diagnosis: an overview of socio-ethical and legal considerations», cit., p. 216.

88 Ver estas dudas en SMOLENSKY, K. R., «Creating children with disabilities: parental tort liability for preimplantation genetic interventions», cit., p. 305.

89 Hace referencia a esta competencia, entre otros, BAYEFSKY, M. J., «Comparative preimplantation genetic diagnosis policy in Europe and the USA and its implications for reproductive tourism», cit., p. 44. Así, por ejemplo, se explica que la mayoría de las clínicas estadounidenses ofrezcan nuevas y más avanzadas técnicas, aunque no estén suficientemente probadas (ALKORTA IDIAKEZ, I., «Regulación de la medicina reproductiva en Norteamérica o el Salvaje Oeste de la Medicina» (Parte I), RDGH, vol. 18, 2003, p. 40 y (Parte 2), vol. 19, 2003, p. 83) o que sean más propensas a satisfacer los deseos (aunque disparatados) de los usuarios de estas técnicas.

90 A ello se refiere SMOLENSKY, K. R., «Creating children with disabilities: parental tort liability for preimplantation genetic interventions», cit., p. 305. 
prohibición plena del ejercicio de la autonomía de la voluntad conduce frecuentemente al incremento de un turismo reproductivo que pone en cuestión la eficacia de la prohibición misma. Insatisfacción de los posicionamientos limitadores de la autonomía de la voluntad, pues los límites ni son uniformes ni son siempre claros en su interpretación o aplicación. Insatisfacción, finalmente, de los posicionamientos pasivos y de ausencia de regulación, que en definitiva equivalen a la plena admisión y reconocimiento del ejercicio de la autonomía de la voluntad, ante la potencial o probada ineficacia de cualquier tipo de limitación no impuesta por los poderes públicos.

En este contexto, por tanto, no se puede afirmar que ninguna solución sea mejor que otra, aunque puedan verse más ventajas en algunas de ellas o, aunque pueda considerarse que algunas responden mejor que otras a una adecuada ponderación de intereses entre la autonomía de la voluntad y la protección de la vida. Esta ponderación, sin embargo, debe ser propia de cada ordenamiento y acorde a sus valores y principios jurídicos y sociales. Por ello, en realidad lo que habrá que propugnar es que, sea cual sea la solución por la que se opte, esta se adopte de forma consciente por parte del ordenamiento en cuestión -es decir, con conciencia de las consecuencias de escoger uno u otro sistema-y sobre la base de lo que resulte tolerable para esa sociedad concreta en este momento histórico determinado.

\section{BIBLIOGRAFÍA}

ABELLÁN, F., «Diagnóstico genético embrionario y libertad reproductiva en la procreación asistida», $R D G H$. , vol. 25, 2006, pp. 21 a 53.

ABELLÁN, F., Selección genética de embriones. Entre la libertad reproductiva y la eugenesia, Granada (Comares), 2007.

ALKORTA IDIAKEZ, I., Regulación jurídica de la medicina reproductiva, Cizur Menor (Thomson-Aranzadi), 2003.

ALKORTA IDIAKEZ, I., «Regulación de la medicina reproductiva en Norteamérica o el Salvaje Oeste de la Medicina» (Parte I), RDGH, vol. 18, 2003, pp. 23 a 41 y (Parte 2), vol. 19, 2003, pp. 41 a 89.

ARANGO RESTREPO, P.; SÁNCHEZ ABAD, P. J. y PASTOR, L. M., «Diagnóstico genético preimplantatorio y el bebé medicamento: criterios éticos encontrados en la literatura biomédica y bioética», Cuadernos de Bioética, vol. 23-2, 2012, pp. 301 a 320 .

BAYEFSKY, M.J., «Comparative preimplantation genetic diagnosis policy in Europe and the USA and its implications for reproductive tourism», Reprod. BioMedicine \& Society Online, vol. 3, 2016, pp. 41 a 47. 
CUADROS, J., «Diagnóstico preimplantacional para evitar la aparición tardía de enfermedades», Rev. Asoc. Est. Biol. Rep., vol. 16-1, 2011, p. 46.

DE LORA DELTORO, P., «¿Es permisible tener un hijo para curar a otro?», BMJ, vol. 2179, 2015, pp. 39 a 64.

EMALDI CIRIÓN, A., «Voz: Diagnóstico preimplantatorio», en ROMEO CASABONA, C. M. (dir.), Enciclopedia de Bioderecho y Bioética, Granada (Comares), 2011 , pp. 630 a 641.

FLORENSA, M., «Diagnóstico genético preimplantacional para enfermedades de aparición tardía», Rev. Asoc. Est. Biol. Rep., vol. 16-1, 2011, pp. 45 a 46.

FOX, D., «Reproductive negligence», Colum. L. Rev., vol. 117, 2017, pp. 149 a 241.

FROMMEL, M., «Die Neuregelung der Präimplantationsdiagnostik durch $\S 3^{\mathrm{a}}$ Embryonenschutzgesetz», JZ, vol. 68-10, 2013, pp. 488 a 495.

GONZÁLEZ MORÁN, L., De la bioética al bioderecho: libertad, vida y muerte, Madrid (Dykinson), 2006.

HARPER, J. C., «Preimplantation genetic screening», J. Med. Screening, 2017, pp. 1-5.

JORQUI AZOFRA, M., «El Tribunal de Cagliari (Italia) da luz verde al diagnóstico genético preimplantacional», RDGH, vol. 27, 2007, pp. 137 a 177.

KNOPPERS, M. M.; BORDET, S. e ISASI, R. M., «Preimplantation genetic diagnosis: an overview of socio-ethical and legal considerations», Annu. Rev. Genom. Hum. Genet., vol. 7-1, 2006, pp. 201 a 221.

KRAMP, A., Arzthaftung bei fehlerhafter Präimplantationsdiagnostik, Baden-Baden (Nomos), 2015.

LACADENA, J. R., «La Ley 14/2006 sobre Técnicas de Reproducción Humana Asistida, consideraciones científicas y éticas», RDGH, vol. 24, 2006, pp. 157 a 184.

LANDEWEERD, L. «Prenatal diagnosis and the trouble with eugenics», RDGH, vol. 30,2009 , pp. 35 a 61.

MACÍA MORILLO, A., Diagnóstico genético preimplantacional y responsabilidad médica por falsos negativos, Madrid (Reus), 2018.

MACÍA MORILLO, A., «Límites penales a la autonomía de la voluntad en la selección embrionaria mediante diagnóstico genético preimplantacional», en CANCIO MELIÁ, M. et al. (coords.), Homenaje al Profesor Agustín Jorge Barreiro, Madrid (UAM Ediciones), 2018 (pendiente de publicación). 
MANCINI, F.; BOADA, M. y BARRI, P. N., «Considerazioni etiche sulla procreazione medicalmente assistita», Revista de Bioética y Derecho, vol. 23, 2011, pp. 35 a 44.

MOROZZO DELLA ROCCA, P., «Tribunale di Catania. Ordinanza 3 maggio 2004. Procreazione medicalmente assistita e beta-talassemia», DFP, vol. 1, 2005, pp. 97 a 104.

OSUNA CARRILLO DE ALBORNOZ, E. y ANDREU MARTÍNEZ, M. B., «Artículo 12. Diagnóstico preimplantacional», en COBACHO GÓMEZ, J. A. (dir.), Comentarios a la Ley 14/2006, de 26 de mayo, sobre Técnicas de reproducción asistida, Cizur Menor (Thomson-Aranzadi), 2007, pp. 435 a 461.

PÉREZ ALONSO, E. J., «Consideraciones críticas sobre la regulación legal de la selección de sexo (Parte I)», RDGH, vol. 16, 2002, pp. 59 a 69.

PÉREZ ALONSO, E. J., «Consideraciones críticas sobre la regulación legal de la selección de sexo (Parte II)», RDGH, vol. 17, 2002, pp. 99 a 124.

PUIGPELAT MARTÍ, F., «La selección de sexo: aspectos jurídicos y valoración crítica», RDGH, vol. 6, 1997, pp. 93 a 110.

RAMOS FUENTES, F. J. y RIBAS MOLINA, M.P.: «Diagnóstico genético preimplantacional», Revista española de pediatría, vol. 63-6, 2007, pp. 443 a 449.

ROMEO CASABONA, C. M., Los genes y sus leyes. El derecho ante el genoma humano, Bilbao-Granada (Comares), 2002.

SANZ, E.; ARREO, V.; DÍAZ, M. V.; MOZO, Y. y ALCOBENDAS, R., «Diagnóstico preimplantacional. Características e indicaciones», Toko-ginecología práctica, vol. 69-3, 2010, pp. 55 a 59.

SMOLENSKY, K. R., «Creating children with disabilities: parental tort liability for preimplantation genetic interventions», Hastings L.J., vol. 60, 2008, pp. 299 a 346.

SOINI, S., «Preimplantation genetic diagnosis (PGD) in Europe: diversity of legislation, a challenge to the community and its citizens», Med. \& Law, vol. 26, 2007, pp. 309 a 323.

SOUTULLO, D., "Selección de embriones y principios de la bioética", $R D G H$, vol. 21, 2004, pp. 185 a 198.

TAUPITZ, J., «§ 3a Präimplantationsdiagnostik. Verordnungsermächtigung», en Embryonenschutzgesetz. Juristischer Kommentar mit medizinisch-naturwissenschaftlichen Grundlagen, 2a ed., Stuttgart (W. Kohlhammer), 2014, pp. 275 a 307.

VIGNEAU, D., «Les dispositions de la loi "bioéthique" du 7 juillet 2011 relatives à $l^{\prime}$ embryon et au foetus humain», $R D$, vol. 32, 2011, pp. 2224 a 2230. 